\title{
A STABLE IMPAIRMENT IN REMOTE MEMORY FOLLOWING ELECTROCONVULSIVE THERAPY
}

\author{
LARRY R. SQUIRE \\ Veterans Administration Hospital and Department of Psychiatry, University of California \\ School of Medicine, La Jolla, California, 92037, U.S.A.
}

(Received 17 May 1974)

\begin{abstract}
Psychiatric patients receiving a course of electroconvulsive therapy for relief of depressive illness were given a test of remote memory for public events covering the years 1940-1969. An impairment in remote memory, covering nearly the entire time period sampled by the test, developed during the first five treatments. This impairment was present during the first hour after the fifth treatment and persisted unchanged for at least twenty-four hours thereafter. Electroconvulsive therapy did not affect performance on the verbal portion of the Weschler Adult Intelligence Scale. Apparenuy, the amnesia produced by electroconvulsive therapy can involve a large portion or perhaps all of remote memory, in addition to recent memory. The relevance of these results to the neural substrates underlying storage and recall is discussed.
\end{abstract}

THE AMNESIC syndrome is characterized by both an anterograde loss of memory for events that occur after the onset of amnesia and by a retrograde memory loss for events that occurred before the onset of amnesia [1-3]. Most observations suggest that retrograde amnesia is brief. For example, in 81 per cent of a series of 1029 head injury cases, retrograde amnesia was estimated to involve only those events occurring within $30 \mathrm{~min}$ of the injury [4]. Loss of memory for events that took place months or years before the onset of amnesia can occur, but an impairment in remote memory has generally been associated with unusually severe head injury [4] and with chronic anterograde amnesia [5-7]. It has also been reported that performance on personal data inventories, which probably involvc remote memory to some degree, is impaired by electroconvulsive therapy (ECT) [8-10]. However, since it is known that a course of ECT can impair performance in some tests of cognitive function [11, 12], it is not clear whether these reports reflect a true defect in remote memory or a broad impairment of intellectual capacity.

It has recently been reported that ECT treatment impaired performance on a test of remote memory for public events, without affecting intelligence test scores [13]. This impairment was observed shortly after the fifth ECT treatment and covered nearly the entire time period (1940-1969) sampled by the test. For these patients anterograde amnesia diminished markedly within a few hours after each ECT treatment [14] and it might be cxpected, therefore, that the remote memory impairment would diminish similarly during the hours after treatment. Indeed, retrograde amnesia typically shrinks following the precipitating incident $[4,6,15]$, and in the case of head trauma, it is clear that considerable shrinkage of retrograde amnesia can occur before the anterograde amnesia has disappeared $[4,15]$. The present study assessed remote memory following ECT up to $24 \mathrm{~h}$ after the first and fifth treatments. The results indicated that remote memory was markedly impaired after a series of five ECT treatments and that this impairment did not change measurably between $40 \mathrm{~min}$ and $24 \mathrm{~h}$ after treatment. 


\section{MATERIALS AND METHODS}

\section{Patients}

The subjects were psychiatric inpatients who had been prescribed a series of bilateral electroconvulsive therapy treatments for the relief of depressive illness. Patients were excluded from the study if they had other psychiatric disorders, neurologic disorders, or if they had received ECT treatment during the previous twelve months. Patients were also excluded if they were born after 1935 . Twenty patients selected according to these criteria were randomly assigned to one of two experimental groups. The patients (60\% female) were aged 38-72 (median age $=52$ ). Decisions as to when treatment should be discontinued were made by the patients' psychiatrists. They had given prior approval for the research project, but did not know which of their patients were participating.

\section{Test and procedures}

A multiple-choice test of remote memory for public events was prepared in two equivalent forms (A and B). The construction of this test has been described in detail previously [16]. Briefly, each form of the test was composed of fifty questions dealing with persons, places, or events that were in the news during the 1940's, the 1950's and the 1960's. Forms A and B each contained 161940 's questions, 171950 's questions and 17 1960 's questions. Because subjects did poorly on this test if they had not lived through the time periods in question [16], it was assumed that the information in the test was acquired close to the time the events occurred, rather than from books and conversations. Sample questions are given in Table 1.

Table 1. Sample questions

1940: Where did the Coconut Grove nightclub fire occur?

(a) Boston (b) Chicago (c) Miami (d) New York

1950: Mike Todd was killed in a
(a) shipwreck
(b) plane crash
(c) car accident
(d) brawl

1960: "The Great Society" was a term used by

(a) John Galbraith (b) Lyndon Johnson (c) Elsa Maxwell

(d) Amy Vanderbilt

Table 2. Testing schedule

\begin{tabular}{|c|c|c|c|}
\hline $\begin{array}{l}\text { ECT } \\
\text { treatment }\end{array}$ & $\begin{array}{l}\text { Time tested } \\
\text { after treatment }\end{array}$ & Group $1(N=10)$ & Group $2(N=10)$ \\
\hline \multirow[t]{2}{*}{$\# 1$} & $40 \mathrm{~min}$ & Remote memory test & ------------ \\
\hline & $24 \mathrm{hr}$ & $\begin{array}{l}\text { Remote memory test } \\
\text { (alternate form) }\end{array}$ & $----\cdots-\cdots-\cdots$ \\
\hline \multirow[t]{2}{*}{$\# 2$} & $40 \mathrm{~min}$ & WAIS ${ }^{*}$ & $-\cdots-----\cdots--$ \\
\hline & $24 \mathrm{hr}$ & W-B II + & $----\cdots-----\cdots$ \\
\hline \multirow[t]{2}{*}{ \# 5} & $40 \mathrm{~min}$ & ----------- & Remote memory test \\
\hline & $24 \mathrm{hr}$ & $----------\cdots$ & $\begin{array}{l}\text { Remote memory test } \\
\text { (alternate form) }\end{array}$ \\
\hline \multirow[t]{2}{*}{ \#6 } & $40 \mathrm{~min}$ & ------------ & WAIS* \\
\hline & $24 \mathrm{hr}$ & ------------ & W-B II $\dagger$ \\
\hline
\end{tabular}

* Wechsler Adult Intelligence Scale, Verbal Portion.

$\dagger$ Wechsler-Bellevue II, Verbal Portion.

The testing schedule is shown in Table 2. Patients in the first group $(N=10)$ took one form of the remote memory test beginning $40 \mathrm{~min}$ after the first ECT treatment and then took the alternate form of the test $24 \mathrm{~h}$ after the first treatment. Patients in the second group $(N=10)$ took one form of the test beginning 40 min after the fifth ECT treatment and then took the alternate form of the test $24 \mathrm{~h}$ after the fifth treatment. Half of the patients in each group took Form A before Form B and half took Form B before Form A. Patients were instructed to answer every question and to guess if necessary.

Patients in the first group were also given the verbal portion of the Wechsler Adult Intelligence Scale (WAIS) beginning $40 \mathrm{~min}$ after the second ECT, and the verbal portion of the Wechsler-Bellevue II (W-B II) beginning about $24 \mathrm{~h}$ after the second ECT. Patients in the second group took the WAIS beginning $40 \mathrm{~min}$ after the sixth ECT, and the W-B Ir beginning about $24 \mathrm{~h}$ after the sixth ECT. Verbal I.Q. ratings were available for only eight of the ten subjects in each group, treatment having been discontinued in the other four cases before all the testing could be completed. 


\section{ECT treatment}

Bilateral ECT treatment was administered in the mornings on Monday, Wednesday, and Friday for each patient. Electrode placement was temporal-parietal. Treatments were given with either an Offner (Type 733) or a Medcraft (Model B-24) ECT machine. Treatment parameters for the Offner machine were $500 \mathrm{~mA}$ for 2-3 sec and for the Medcraft machine, $140-160 \mathrm{~V}$ for $0.75 \mathrm{sec}$. Half of the patients in each group received all their treatments with one of the ECT machines and half of the patients received all their treatments with the other machine. Following premedication with atropine $(0.8 \mathrm{mg})$, ECT was administered under barbiturate anesthesia (sodium methohexitone, $60 \mathrm{mg}$ ), full muscular relaxation (succinyl choline, 30-40 mg), and oxygen supply. In all cases the patient was described by the attending physician as having a well-modified grand mal seizure.

\section{RESULTS}

During the course of the first five ECT treatments, patients developed a marked deficit in their ability to recall past events. This deficit in remote memory appeared across nearly the entire time period sampled by the test. Figure 1 (left) compares patients tested $40 \mathrm{~min}$
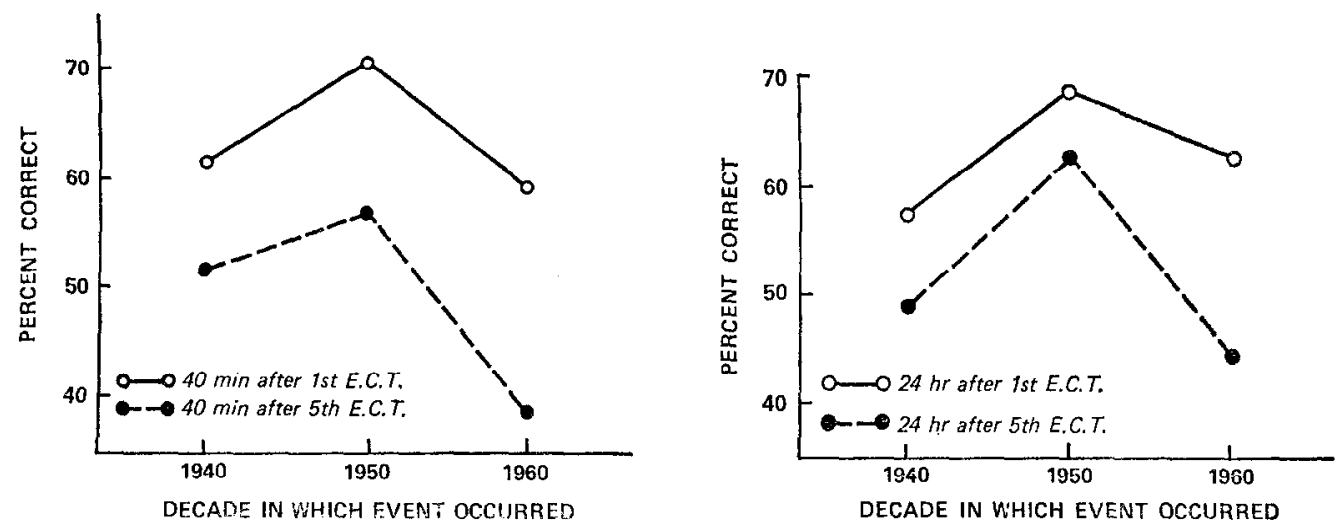

FIG. 1. A test of remote memory for public events was administered to two groups of psychiatric patients receiving a series of ECT treatments for relief of depressive illness. The two groups were tested on two occasions: at $40 \mathrm{~min}$ after their first or fifth treatments (Fig. 1, left) and at $24 \mathrm{hr}$ after their first or fifth treatments (Fig. 1, right). Patients tested 40 min after their fifth treatment $(N=10)$ were impaired relative to patients tested after their first treatment $(N=10)$ regardless of when the remote memory test was administered (for the $40 \mathrm{~min}$ test, $F=8.3, P<0.05$; for the $24 \mathrm{hr}$ test time, $F=5.8, P<0.05$ ).

after their first treatment with patients tested 40 min after their fifth treatment; and Fig. 1 (right) compares patients tested $24 \mathrm{~h}$ after their first treatment with patients tested $24 \mathrm{~h}$ after their fifth treatment. An analysis of variance with repeated measures on one factor [17] revealed a significant effect of ECT treatment on remote memory. For patients taking the remote memory test 40 min after treatment (Fig. 1, left), the effect of ECT treatment was significant $(F=8 \cdot 3, d f=1 \cdot 18, P<0 \cdot 05)$. An analysis of simple main effects indicated that this difference was significant for the 1950's $(F=4.4, P<0.05)$ and for the 1960 's $(F=10.4 P<0.01)$. For patients taking the remote memory test $24 \mathrm{hr}$ after treatment, the effect of ECT treatment was also significant $(F=5.8, d f=1 \cdot 18, P<0.05)$. The difference between groups was significant only for the 1960 's $(F=6 \cdot 7, P<0 \cdot 01)$.

Figure 2 permits a direct comparison of remote memory test scores within each patient group. An analysis of variance with repeated measures on two factors [18] indicated that performance $40 \mathrm{~min}$ and $24 \mathrm{~h}$ after ECT was not significantly different (Fig. 2, left, $F=0 \cdot 1$, $d f=1 \cdot 9$; Fig. 1, right, $F=0 \cdot 7, d f=1 \cdot 9$ ). Taken together, the present results indicated that a remote memory deficit could be detected shortly after the fifth ECT treatment and that 

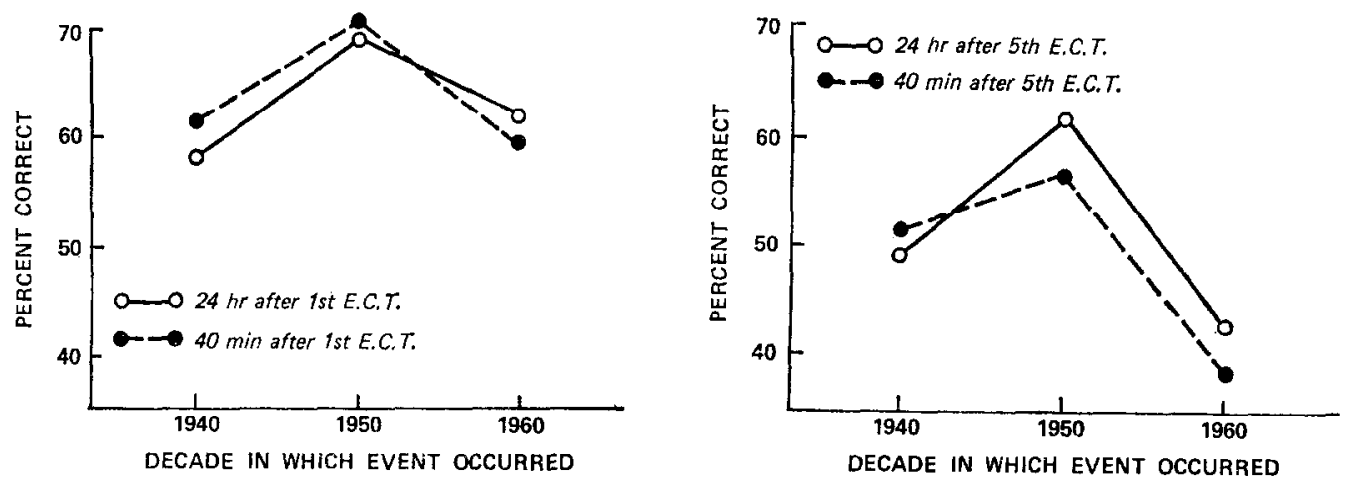

FIG. 2. Comparisons of patients taking the remote memory test $40 \mathrm{~min}$ and $24 \mathrm{hr}$ after their first ECT treatment (Fig. 2, left, $N=10$ ) or $40 \mathrm{~min}$ and $24 \mathrm{hr}$ after their fifth treatment (Fig. 2, right, $N=10$ ). None of these comparisons is statistically significant (for patients tested after their first treatment, $F=0 \cdot 1$; for patients tested after their fifth treatment, $F=0.7$ ).

Table 3. Intelligence test performance following ECT

\begin{tabular}{ccc}
\hline & Tested after 2 nd ECT & Tested after 6th ECT \\
Median age & 53 & 55 \\
(Range) & $(43-71)$ & $(38-74)$ \\
$\begin{array}{c}\text { Median verbal I.Q. } \\
40 \text { min after ECT } \\
\text { (Range) }\end{array}$ & 102 & 97 \\
$\begin{array}{c}\text { Median verbal I.Q. } \\
\text { 24 hr after ECT } \\
\text { (Range) }\end{array}$ & $(78-147)$ & $(78-117)$ \\
\hline
\end{tabular}

this deficit persisted unchanged for at least $24 \mathrm{~h}$.

The results for the I.Q. tests are illustrated in Table 3. The group tested $40 \mathrm{~min}$ and $24 \mathrm{~h}$ after the second ECT treatment achieved median scores of 102 and 101, respectively. The group tested 40 min and $24 \mathrm{~h}$ after the sixth ECT treatment achieved median scores of 97 and 99, respectively. The largest difference between any of the groups was 5 I.Q. points, and none of the between-group or within-group differences approached statistical significance. A non-significant loss of 5 points in verbal I.Q. has also been observed when patients were tested with the WAIS before the first treatment and again with the same test beginning 40 min after the sixth treatment.*

\section{DISCUSSION}

The results indicated that ECT treatment produced a marked impairment in remote memory in the absence of a measurable change in intelligence test performance. The difference in verbal I.Q. scores between patients tested before or after the onset of the remote memory impairment was only 5 points, and not statistically significant. This finding is in agreement with the report that patients tested within $48 \mathrm{~h}$ after their sixth ECT treatment performed at their pre-ECT level on three verbal subtests of the WAIS [12]. Even if the 5-point difference in the present study were significant, it could not be a factor in the remote memory deficit, since a change of $5 \mathrm{I}$.Q. points is correlated with a drop of only 2 per cent in performance on the remote memory test [13]. The retrograde amnesia for

\footnotetext{
* Unpublished observations $(N=7)$.
} 
remote events is stable and unchanged for at least $24 \mathrm{~h}$ after treatment. It is not yet clear how much longer than $24 \mathrm{~h}$ this amnesia lasts. In one study of memory for past personal events, recovery was not complete even 10-14 weeks following the cessation of treatment [9]. A long-term follow-up study directed at this important question is now in progress.

A remote memory impairment has not been included in the traditional description of the organic amnesic syndrome, except in cases of persisting anterograde amnesia [5-7]. The amnesia produced by ECT is neither chronic, nor does it seem unusually severe. Most patients remained generally oriented through their series of treatments, and in all cases anterograde amnesia markedly diminished between treatments [14]. Therefore, the fact that ECT could produce a prolonged and stable remote memory impairment suggests that at least some forms of amnesia can affect remote memories as well as recent memories. If so, one reason that a remote memory deficit might have been overlooked in the past is that tests specifically designed to probe remote memory have rarely been used. In addition, informal questioning about personal past history can be misleading. Such interviews tend to rely on questions concerning information that is well-rehearsed and over-learned. Indeed, such an interview of the patients in the present study might have suggested that these patients had normal remote memory. All these patients named their birthplace accurately and conversed in a rational manner at the beginning of the test sessions. In fact, they apparently had command of a good deal of well-rehearsed and over-learned information, because they were able to obtain normal scores on the verbal I.Q. tests.

When remote memory is impaired, Ribot [19] argued that memory for events occurring many years ago is less impaired than memory for events occurring only a few years ago. By this view, memory somehow becomes more invulnerable over the years so that the oldest memories are the most resistant to disruption. Some observations of amnesic patients have been interpreted as supporting Ribot's hypothesis $[4,20]$ and some theoretical ideas about long-term memory have been developed recently, which incorporate that point of view [21]. However, it is difficult to test such a hypothesis decisively either with informal interviews or with presently available tests of remote memory. As discussed in detail previously $[13,16]$, the possibility that sampling biases may operate in the selection of questions from different time periods makes it difficult to compare the results for one time period with those for another. Accordingly, the findings that Korsakoff's syndrome [7] and ECT [13] impair performance on 1940's questions as much as they impair performance on 1960's questions should not be taken as evidence against Ribot's hypothesis. It is hoped, however, that improved methods of test construction [22] will allow a proper examination of the temporal dimension of long-term memory.

Aside from the relevance of the present results to theories of long-term memory, these results also bear on current notions of short-term memory and consolidation. Perhaps because the amnesic effects of electroconvulsive treatment on recent memory are so easy to document, this agent has often been used in attempts to obtain an estimate of the consolidation period, the hypothetical interval required for conversion of memory from a short-term, labile form into a more permanent long-term store. Estimates of the length of this time period have been derived from studies in which convulsive stimulation is administered at a variable interval after training [cf. 23, 24]. By this strategy, the consolidation time is the minimal training-treatment interval consistent with normal retention. Although estimates of consolidation time derived in this manner have varied considerably [see 25], it has generally been agreed that at some time after learning, memory becomes invulnerable to convulsive treatment. In fact, there seems to be a prevailing belief in the 
literature of memory that long-term memory is relatively invulnerable to amnesic treatment. One factor that may have tended to maintain this belief is that in animal studies disturbances in long-term memory are difficult to distinguish from non-specific decrements in the ability to perform. In addition, the notion that long-term memory is stable is consistent with the finding that performance on many tasks is not affected by treatments that presumably can markedly disrupt neural function $[26,27]$. The present results indicate quite clearly, however, that long-term memory is vulnerable to the effects of electroconvulsive treatment. Accordingly, probably very little can be concluded from the results of experiments with this agent about either the biological basis of short-term memory or its time course. The present results are of interest primarily because they indicate that long-term memory can be impaired, and that this impairment can occur in the absence of changes in intelligence test scores.

In the past few years it has been popular to explain amnesia by attributing the difficulty to either a disturbance of storage or to a disturbance of retrieval. Explanations in terms of storage mechanisms have tended to view amnesia as a failure of memory consolidation [cf. 28-30]. Explanations in terms of retrieval mechanisms have viewed amnesia as a failure of retrieval from long-term memory [31-33]. The fact that ECT produces a rather global defect in recall, that apparently extends to material learned many years before treatment, means that this defect cannot easily be explained as a failure of consolidation. The accumulation of more precise information about the molecular changes underlying memory storage and about the susceptibility of these changes to amnesic agents should allow a clearer understanding of amnesia. In the meantime, it seems premature to attribute a deficit in recall ability exclusively to a defect in the stored information itself or to an impairment in some hypothetical retrieval process [25].

On the basis of many thoroughly studied cases of human memory pathology, the suggestion has been made that medial temporal and diencephalic structures constitute an essential anatomical substrate for the consolidation of newly acquired information [34-36]. In view of the fact that ECT produces electrophysiological abnormalities in the temporal region [37], it is interesting to speculate that these same structures, which appear to be required for the storage and processing of newly acquired information, may also be required for the efficient recall of information from remote memory.

Acknowledgemenis--I thank SitPhen Chapin, Patkicta Hadl and Deborah Mullen for their assistancc with interviews. PHILIP Roll for the construction of computer programs, and IRwIN LEviTAN for critical editorial comments. I am also grateful to the staff of Mesa Vista Psychiatric Hospital and Mercy Hospital, Psychiatric section, for their full cooperation. Supported by NIMH grants MH18282 to S. H. Barondes and MH24600 to the author, by a grant from the A. P. Sloan Foundation, and by a Clinical Investigatorship (8084-C) from the Veterans Administration to the author.

\section{REFERENCES}

1. Barbizet, J. Human Memory and Its Pathology. Freeman, San Francisco, 1970.

2. Tali and, G. A. Deranged Memory. Academic Press, New York, 1965.

3. Zangwill, O. The amnesic syndrome. In Amnesia. C. W. M. WhitTY and O. L. Zangwill (Editors), Butterworths, London, 1966.

4. Russell, W. R. and Nathan, P. W. Traumatic amnesia. Brain 69, 280-300, 1946.

5. Benson, D. F. and Geschwind, N. Shrinking retrograde amnesia. J. Neurol., Neurosurg. Psychiat. 30, 539-544, 1967.

6. Rose, F. C. and Symonds, C. P. Persistent memory defect following encephalitis. Brain 83, 195-212, 1960.

7. Sanders, H. and Warrington, E. K. Memory for remote events in amnesic patients. Brain 94, 661-668, 1971.

8. Bidder, T. G., Strain, J. J. and Brunschwig, L. Bilateral and unilateral ECT: follow-up study and critique. Am. J. Psychiat. 127, 737-745, 1970. 
9. JANIS, I. L. Psychologic effects of electric convulsive treatments. J. nerv. ment. Dis. 3, 359-383, 1950.

10. StiePer, D. R., Williams, M. and Duncan, C. P. Changes in impersonal and personal memory following electroconvulsive therapy. J. clin. Psychol. 7, 361-366, 1951.

11. Kendall, B. S., Milis, W. B. and Thale, T. Comparison of two methods of electroshock in their effect on cognitive functions. J. Consult. Psychol. 6, 423-429, 1956.

12. McAndrew, J., Berkey, B. and Matrhews, C. The effects of dominant and non-dominant unilateral ECT as compared to bilatcral ECT. Am. J. Psychiat. 124, 69-76, 1967.

13. SQUiRe, L. R. Prolonged retrograde amnesia following electroconvulsive therapy. Behav. Biol. (In press).

14. SQutre, L, R. and Miller, P. L. Diminution of anterograde amnesia following electroconvulsive therapy. Br. .J. Psychiat. (In press).

15. Russell, W. R. The Traumatic Amnesias. Oxford, London, 1971.

16. SQuire, L. R. Remote memory as affected by aging. Neuropsychologia 12, 429-435, 1974.

17. Wiener, B. J. Statistical Principles in Experimental Design. McGraw-Hill, New York, 1962.

18. McNemar, Q. Psychological Statistics. 3rd Edn. Wiley, New York, 1962.

19. Riвot, T. Diseases of Memory. Appleton, New York, 1882.

20. ZANGWILl, O. Amnesia and the generic image. Q.J. exp. Psychol. 2, 7-12, 1950.

21. Wickelgren, W. A. Trace resistance and the decay of long-term memory. J. Math. Psychol. 9, 418-454, 1972.

22. Squire, L. R. and Slater, P. C. Forgetting in very long-term memory as assessed by an improved questionnaire technique. J. exp. Psychol. Human Memory. (In press.)

23. JARVIK, M. E. Effects of chemical and physical treatments on learning and memory. Ann. Rev. Psychol. 23, 457-486, 1972.

24. MCGaugh, J. L. and Herz, M. M. (Editors) Memory Consolidation. Albion, San Francisco, 1972.

25. Squtre, L. R. Short-term memory as a biological entity. In Short-term Memory. D. Deutsch and J. A. Deutsch (Editors), Academic Press, New York, in press.

26. Nielsen, H. C., Zimmerman, J. M. and Colliver, J. C. Effect of complete arrest of cerebral circulation on learning and retention in dogs. J. comp. Physiol. Psychol. 56, 974-978, 1963.

27. Sperry, R. W. and Miner, N. Pattern perception following insertion of mica plates into visual cortex. J. comp. Physiol. Psychol. 48, 463-469, 1955.

28. McGaugh, J. L. Time-dependent processes in memory storage. Science, N.Y. 153, 1351-1358, 1966.

29. CHERKIN, A. Retrograde amnesia: impaired memory consolidation or impaired retrieval? Comm. Behav. Biol. 5, 183-190, 1970.

30. McGaugh, J. L. and Dawson, R. G. Modification of memory storage processes. Behav, Sci. 16, $45-63,1971$.

31. LEWIS, D. J. Sources of experimental amnesia. Psychol. Rev. 76, 461-472, 1969.

32. Miller, R. R. and Springer, A. D. Amnesia, consolidation and retrieval. Psychol. Rev. 80, 69-79, 1973.

33. Spear, N. E. Retrieval of memory in animals. Psychol. Rev, 80, 163-194, 1973.

34. Adams, R. D., Collins, G. H, and Victor, M. Troubles de la mémoire et de l'apprentissage chez l'homme; leurs relations avec dés lesions dés lobes temperaux et du diencéphale. In Physiologie de l'hippocampe. Centre National de la Recherche Scientifique, Paris, 1962.

35. Mitner, B. Amnesia following operation on the temporal lobes. In Amnesia. C. W. M. WhitTY and O. L. ZANGWILL (Editors), Butterworths, London, pp. 109-133, 1966.

36. VAN BUREN, J. J. and Borkc, R. C. The mesial temporal substratum of memory. Brain 95, 595-632, 1972.

37. INGLIs, J. Shock, surgery, and cerebral asymmetry. Br. J. Psychiat., 117, 143-148, 1970.

Zusammenfassung - Psychiatrische Patienten in elektrokonvulsiver Therapie für Depressionen wurden auf ihr Erinnerungsvermögen an öffentliche Geschehnisse der Jahre 1940 bis 1969 geprüft. Eine Reduktion des Erinnerungsvermögens für beinahe die ganze Zeitperiode der Prüfung entwickelte sich während der ersten fünf Behandlungen. Diese Verminderung wurde während der ersten Stunde nach der fünften Behandlung gefunden und dauerte unverändert mindestens vierundzwanzig Stunden an. Elektrokonvulsive Therapie hatte keinen Einfluss auf den mündlichen Teil der Wechsler Intelligenzskala für Erwachsene. Die Einflüsse dieser Mittcl sind scheinbar nicht auf neue Lernfähigkeiten und kurzfristiges Erinnerungsvermögen beschränkt, sondern können sich auch auf einen grossen Teil oder möglicherweise sogar auf das gesamte Erinnerungsvermögen an lang vergangene Geschehnisse ausdehnen. Die Bedeutung dieser Resultate für das Nervensubstrat der Aufspeicherung und des Widerrufes werden diskutiert.

Résumé-La mémoire lointaine de certains évènements publiques arrivés entre 1940-1969 a été examinée chez des patients psychiatriques soumis à une série de traîtements électroconvulsifs. Une dysfonction de la mémoire lointaine, concernant presque toute la période 
étudiée par l examen, s'est développée au cours des cinq premiers traîtements. Cette dysfonction présente durant la première heure après le cinquième traîtement, persista inchangée peudant au moins les vingt-quatre heures suivantes. La thérapie électroconvulsive n'a pas modifié le résultat de la partie verbale de l'échelle d'intelligence pour adultes de Wechsler. Apparemment les effets de l'électrochoc ne sont pas limités à l'apprentissage et à la mémoire récente, mais peuvent aussi s'étendre à une large portion ou peut-être même à toute la mémoire lointaine. La signification de ces résultats en fonction des substrats nerveux responsables de l'acquisition et du rappel est discutée. 